\title{
Regional Impact of Geography on Home Dialysis Utilization
}

Eric L. Wallace ${ }^{1^{*}}$, Russell L. Griffin ${ }^{2}$, Kelly L. Koenig ${ }^{3}$ and Lauren A. Crain ${ }^{3}$

${ }^{1}$ Department of Medicine, Division of Nephrology, University of Alabama at Birmingham, Birmingham, Alabama, USA

${ }^{2}$ Department of Epidemiology, University of Alabama at Birmingham, Birmingham, Alabama, USA

${ }^{3}$ Department of Geography, University of Alabama, Tuscaloosa, Alabama, USA

"Corresponding author: Eric L. Wallace, Department of Medicine, Division of Nephrology, University of Alabama, 728 Richard Arrington Blvd., 229 Paula Building, Birmingham, Alabama 35294, USA, Tel: (205) 975-9676; Fax: (205) 975-8879; E-mail: ericlwallace@uab.edu

Rec date: June 17, 2014, Acc date: July 10, 2014, Pub date: July 15, 2014

Copyright: ( 2014 Wallace EL, et al. This is an open-access article distributed under the terms of the Creative Commons Attribution License, which permits unrestricted use, distribution, and reproduction in any medium, provided the original author and source are credited.

\begin{abstract}
Objectives: Studies evaluating geographic barriers to home dialysis utilization in the United States have shown increased rates of utilization of home therapies in rural areas and increased distance to a home dialysis unit (HDU). These large studies may not capture unique regional variation in access to home dialysis. We performed this study to evaluate geographic barriers to home dialysis in the rural Southeastern US.
\end{abstract}

Methods: We extracted residential zip code and dialysis modality on point-prevalent dialysis patients living in Alabama, Mississippi, and Tennessee. Facility location was identified as well. Data were stratified by patient zip code using Rural Urban Continuum Codes (RUCC) and by circumferential zones differentiated by distance around existing (HDU). 2010 U.S. census data was used for socioeconomic characteristics of each zone. Poisson regression was used to compare prevalence of home dialysis by circumferential zone and RUCC.

Results: Patients more rural or remote from a HDU had higher end-stage renal disease rates, lower median per capita income, higher poverty levels, and were older compared to those within 20 miles of a HDU or urban (all $p$ values <0.001). The adjusted prevalence ratio of home modalities (PD and $\mathrm{HHD}$ ) was $1.14(95 \% \mathrm{Cl} 1.03-1.26)$ in RUCC codes $4-7$, and $1.00(95 \% \mathrm{Cl}, 0.80-1.24)$ for RUCC code $8-9$ when compared to the most urban (RUCC 1-3). There was no difference in adjusted prevalence ratio of home modality utilization regardless of distance to the closest HDU $(1.02 ; 95 \% \mathrm{Cl} 0.90-1.16,0.87 ; 95 \% \mathrm{Cl} 0.72-1.05$, and $0.96 ; 95 \% \mathrm{Cl} 0.69-1.34$ for $20-30,30-40$, and $>40$ miles respectively) when compared to patients within 20 miles of an HDU.

Conclusions: Prevalence ratio of home dialysis did not differ with distance from an HDU and did not increase in rural areas versus metropolitan areas. Further studies are needed to address if regional variation exists in access to home dialysis care.

Keywords: Peritoneal dialysis; Geographic disparities; Rural access to care; Epidemiology of home dialysis

\section{Introduction}

Home dialysis (peritoneal dialysis and home hemodialysis) is markedly under-utilized in the U.S., accounting for only $7.5 \%$ of the prevalent dialysis population [1]. Several studies have identified major remediable barriers to home dialysis, including inadequate nephrology training, absence of pre-dialysis education of patients on dialysis options, and high technique failure rates [2-5]. The impact of geography on utilization of home dialysis has received fairly limited attention in the United States.

Home dialysis would seem to be particularly advantageous among patients living in rural areas, as it may obviate the need for timeconsuming travel to an in-center hemodialysis unit. Not surprisingly, two large studies evaluating the effect of geography on home dialysis utilization have found increased utilization in more rural areas or with increasing distance to a home dialysis unit. O'Hare et al. found that utilization of PD was higher in rural compared to urban areas (19\% vs. 11\%) when looking at the United States in aggregate [6]. More recently, Prakash et al. also showed an increase in home dialysis utilization for patients living farther from a home dialysis facility [7]. However, as the geographic and socioeconomic circumstances are varied across the United States, so may access to home dialysis care. As such, studies such as those mentioned looking at large countries in aggregate may not address unique situations in smaller geographic divisions with more similar characteristics such as the southeastern United States.

With this in mind, the purpose of this study was to address the prior limitations of rural home dialysis utilization and determine if distance to a home dialysis or rural/urban designation affected the rates of home dialysis utilization in the largely rural Network 8 (Alabama, Mississippi, and Tennessee).

\section{Materials and Methods}

\section{Study design}

The United States Renal Data System data acquisition is performed by subdividing the country into End Stage Renal Disease Networks. Each network collects data on all ESRD patients within that network. Point prevalent data from the Consolidated Renal Operations in a Web-enabled Network (CROWNWeb) dataset including patient 
modality and zip code were used from dialysis Network 8 taken in July of 2013. Both incident and prevalent patients were included. Facility data from December 2012 with facility census by modality and zip codes were also obtained from Dialysis Network 8 . Home dialysis was defined as both home hemodialysis and peritoneal dialysis. A unit was designated as a home dialysis unit (HDU) if it both was certified for home dialysis therapy and had at least one prevalent home dialysis patient. Rural Urban Continuum Codes (RUCC) - designations by which counties are classified by number ranging from 1 to 9 with 1 being a populous metropolitan (metro) county and 9 being the most remote rural county-were obtained from the Economic Research Service 2012 data set. U.S. 2010 Census data from the American Community Survey were used to establish socioeconomic characteristics and total population for each zip code.

\section{Exposure variable}

The two geographic exposure variables of interest were i) RUCC code grouping by metropolitan (1-3), micropolitan (4-7), and rural (8-9), and ii) circumferential zones around all existing HDU designated as within 20, 20-30, 30-40, and greater than 40 miles. For the circumferential zone analysis, HDU were identified by zip code and geo-referenced to the center of the zip code. Multiple HDUs within a single zip code were treated as a single central point within that zip code such that a zip code has a center(s) or it does not. Patient data was, in a like manner, geo-referenced to the centroid of their residential zip code. The total number of patients within the residential zip code was tagged with this data attribute. Circular buffers around the dialysis centers were then generated at a desired diameter. Residential zip code centroids that fell beyond the periphery of the buffers were summed to arrive at a total number of patients who lived outside the buffer.

\section{Statistical Methods}

Census characteristics were compared by the exposure variables of interest using an ANOVA. Poisson regression was used to estimate prevalence ratios (PR) and associated 95\% confidence intervals $(95 \%$ $\mathrm{CI}$ ) for the association between rurality defined by RUCC and comparator geographic zones and prevalence of home dialysis utilization (per total population). Poisson models were adjusted for median age, race distribution, median per capita income, unemployment percentage, and percentage of population under the poverty level. A p-value of $<0.05$ was considered statistically significant, and SAS v9.3 was used for all analyses.

\section{Results}

\section{Descriptive analysis}

The total point prevalent dialysis population of Network 8 was 23,692. Of those, 2347 were on either peritoneal dialysis or home hemodialysis. 157 out of 411 facilities in Alabama, Mississippi, and Tennessee were certified to provide home dialysis care. 135 out of 157 HDU had at least 1 patient using a home dialysis modality. Of those 40 (30\%) had less than 5 patients, $23(17 \%)$ had between 6 and 10 patients, $29(21 \%)$ between 11 and 20 patients, 29 (21.5\%) between 21 and 50 , and $14(10.4 \%)$ greater than 50 patients. HDU with more than 20 patients represent only $32 \%$ of the units, but care for $75.7 \%$ of patients on home modalities (Figure 1).

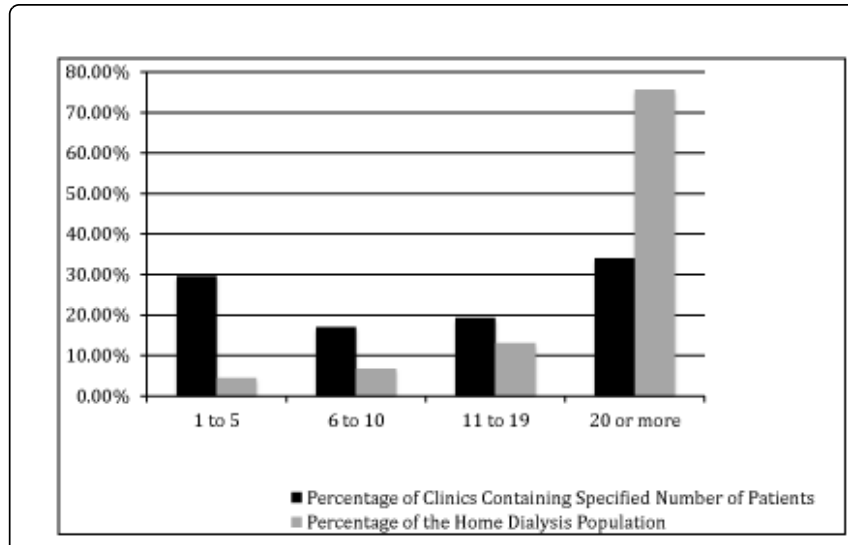

Figure 1: Home dialysis units by their size in relation to the percentage of the dialysis population cared for

\section{RUCC analysis}

Zip codes with counties classified as metropolitan had a younger population than those classified as micropolitan or rural $(\mathrm{p}<0.0001)$ (Table 1). Metropolitan counties additionally had higher per-capita income $(\mathrm{p}<0.0001)$, a higher proportion of the population graduating high school $(p<0.0001)$, lower unemployment $(p=0.0003)$, and a lower percentage below poverty $(\mathrm{p}<0.0001)$. Counties classified as rural had a lower proportion of individuals reporting white race $(\mathrm{p}<0.0001)$ and higher proportion reporting African-American race $(\mathrm{p}<0.0001)$. The prevalence of peritoneal dialysis was lowest for metropolitan RUCCs (16.06 per 1,000,000 11 population) and highest for micropolitan RUCCs (19.22 per 1,000,000 population). Compared to metropolitan RUCCs, micropolitan RUCCs had a 20\% higher prevalence of home dialysis use (PR 1.20, 95\% CI 1.09-1.31), an association that remained after adjusting for census characteristics (PR 1.14, 95\% CI 1.03-1.26). There was no difference in the prevalence of home dialysis between metropolitan and rural areas although limited numbers of patients in rural areas may limit the power to detect such a difference.

\begin{tabular}{|l|l|l|l|l|}
\hline Continuum Code & (RUCC) & & & \\
\hline & RUCC & RUCC & RUCC & \\
\hline & $1-3$ & $4-7$ & $8-9$ & \\
\hline Percent of total population & Metro & Micro & Rural & p-value \\
\hline All States & $69.77 \%$ & $26.32 \%$ & $3.91 \%$ & \\
\hline Alabama & $75.70 \%$ & $21.32 \%$ & $2.98 \%$ & \\
\hline Mississippi & $45.12 \%$ & $46.42 \%$ & $8.46 \%$ & \\
\hline Tennessee & $76.81 \%$ & $20.71 \%$ & $2.48 \%$ & \\
\hline Census characteristics & & & & \\
\hline Mean age (years) & 38.58 & 40.01 & 40.42 & $<0.0001$ \\
\hline Mean percent race & & & $63.49 \%$ & $<0.0001$ \\
\hline White & $74.01 \%$ & $72.94 \%$ & & \\
\hline
\end{tabular}


Citation: Wallace EL, Griffin RL, Koenig KL, Crain LA (2014) Regional Impact of Geography on Home Dialysis Utilization. J Nephrol Ther 4: 176. doi:10.4172/2161-0959.1000176

Page 3 of 5

\begin{tabular}{|c|c|c|c|c|}
\hline AA & $22.29 \%$ & $24.56 \%$ & $34.34 \%$ & $<0.0001$ \\
\hline Hispanic & $3.04 \%$ & $2.12 \%$ & $1.01 \%$ & $<0.0001$ \\
\hline Mean Per Capita Income & $\$ 46,084$ & $\$ 34,595$ & $\$ 32,266$ & $<0.0001$ \\
\hline $\begin{array}{l}\text { Mean \% graduated high } \\
\text { school }\end{array}$ & $72.80 \%$ & $69.25 \%$ & $66.94 \%$ & $<0.0001$ \\
\hline Mean \% unemployment & $5.73 \%$ & $6.50 \%$ & $6.05 \%$ & 0.0003 \\
\hline $\begin{array}{l}\text { Mean \% below poverty } \\
\text { level }\end{array}$ & $13.36 \%$ & $17.98 \%$ & $20.65 \%$ & $<0.0001$ \\
\hline \multicolumn{5}{|l|}{ Modality } \\
\hline $\begin{array}{l}\text { ESRD prevalence (per } \\
\text { million) }\end{array}$ & $1,651.85$ & $1,848.08$ & $1,976.07$ & $<0.0001$ \\
\hline Mean \% hemodialysis & $88.29 \%$ & $87.82 \%$ & $90.84 \%$ & \\
\hline Mean \% home dialysis & $11.71 \%$ & $12.18 \%$ & $9.16 \%$ & \\
\hline Prevalence rate of PD & 16.06 & 19.22 & 18.76 & \\
\hline $\begin{array}{l}\text { Crude prevalence ratiot } \\
\left(\begin{array}{llll}95 \% & \mathrm{Cl}) & \text { of } & \text { home } \\
\text { dialysis } & & \end{array}\right.\end{array}$ & Ref & $\begin{array}{l}1.20 \\
(1.09-1.31)\end{array}$ & $\begin{array}{l}1.18 \\
(0.96-1.45)\end{array}$ & \\
\hline 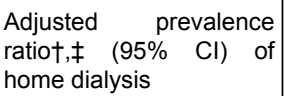 & Ref & $\begin{array}{l}1.14 \\
(1.03-1.26)\end{array}$ & $\begin{array}{l}1.00 \\
(0.80-1.24)\end{array}$ & \\
\hline
\end{tabular}

Table 1: Comparison of population and dialysis characteristics by Rural Urban

\section{* Estimated from ANOVA}

$\dagger$ Estimated from Poisson regression

¥ Adjusted for median age, race distribution, median per capita income, $\%$ unemployment, and $\%$ of population under the poverty level.

\section{Comparator zone analysis}

$19.84 \%$ of the total population and $20.6 \%$ of the ESRD population live outside of a 20 mile radius from a HDU. Zip codes within 20 miles of a HDU had a lower median age $(\mathrm{p}=0.0002)$, higher per capita income $(\mathrm{p}<0.0001)$, and a lower percentage of the population below the poverty line $(\mathrm{p}=0.0009)$ compared to other comparator zones

(Table 2). ESRD prevalence was highest for zip codes $>40$ miles from the nearest $\mathrm{HDU}$ ( $\mathrm{p}<0.0001$ for both modalities).

Although there appeared to be a stepwise decrease in the percentage of ESRD patients on home dialysis in zones 30-40 miles and $>40$ miles from a dialysis unit, this trend did not reach statistical significance (Table 3). Figure 2 shows, the cartographic representation of the data.

\begin{tabular}{|c|c|c|c|c|c|}
\hline & $\begin{array}{l}\text { Inside } \\
\text { 20miles }\end{array}$ & $\begin{array}{l}20-30 \\
\text { miles }\end{array}$ & $\begin{array}{l}30-40 \\
\text { miles }\end{array}$ & $\begin{array}{l}>40 \\
\text { miles }\end{array}$ & $p$-value* \\
\hline \multicolumn{6}{|c|}{ Percent of Total Population } \\
\hline Alabama & $81.82 \%$ & $12.92 \%$ & $5.02 \%$ & $0.25 \%$ & \\
\hline Mississippi & $61.30 \%$ & $19.26 \%$ & $13.11 \%$ & $6.33 \%$ & \\
\hline Tennessee & $87.84 \%$ & $9.20 \%$ & $2.71 \%$ & $0.24 \%$ & \\
\hline All States & $80.16 \%$ & $12.60 \%$ & $5.70 \%$ & $1.54 \%$ & \\
\hline \multicolumn{6}{|c|}{ Census Characteristics } \\
\hline Median age Race & 38.81 & 40.08 & 40.84 & 40.11 & 0.0002 \\
\hline White & $72.09 \%$ & $72.11 \%$ & $74.65 \%$ & $70.41 \%$ & 0.6986 \\
\hline AA & $24.57 \%$ & $25.30 \%$ & $22.95 \%$ & $26.80 \%$ & 0.8019 \\
\hline Hispanic & $2.71 \%$ & $2.04 \%$ & $2.01 \%$ & $1.03 \%$ & 0.0009 \\
\hline $\begin{array}{l}\text { Median Per Capita } \\
\text { Income }\end{array}$ & $\$ 43,078$ & $\$ 35,272$ & $\$ 33,513$ & $\$ 32,141$ & $<0.0001$ \\
\hline $\begin{array}{l}\text { Mean \% graduated } \\
\text { high school }\end{array}$ & $71.35 \%$ & $69.63 \%$ & $69.74 \%$ & $69.45 \%$ & 0.2278 \\
\hline \%Unemployment & $5.95 \%$ & $6.31 \%$ & $6.16 \%$ & $6.22 \%$ & 0.3863 \\
\hline $\begin{array}{l}\% \quad \text { below the } \\
\text { poverty level }\end{array}$ & $15.12 \%$ & $17.56 \%$ & $17.44 \%$ & $18.54 \%$ & 0.0009 \\
\hline $\begin{array}{l}\text { ESRD Prevalence } \\
\text { in rate } / 1,000,000\end{array}$ & 1,698 & 1,772 & 1,739 & 2,101 & $<0.0001$ \\
\hline
\end{tabular}

Table 2: Comparison of census characteristics of zip codes by distance to nearest home dialysis unit

${ }^{*}$ Estimated from ANOVA for all variables except ESRD prevalence, which was compared among radius categories using a Poisson regression

\begin{tabular}{|l|l|l|l|l|}
\hline & Inside 20 miles & $20-30$ miles & $30-40$ miles & $>40$ miles \\
\hline $\mathrm{N}$ & 18,795 & 3,082 & 1,369 & 446 \\
\hline \%of total ESRD Population & $79 \%$ & $13 \%$ & $6 \%$ & $2 \%$ \\
\hline$\%$ Home & $10.00 \%$ & $10.10 \%$ & $9.30 \%$ & $8.30 \%$ \\
\hline$\%$ In Center Hemo & $90.00 \%$ & $89.90 \%$ & $90.70 \%$ & $91.70 \%$ \\
\hline Home dialysis prevalence (per 1,000,000 persons) & 16.92 & 17.88 & 16.14 & 17.43 \\
\hline Crude prevalence ratio* $(95 \% \mathrm{Cl})$ of home dialysis & Ref & $1.06(0.94-1.20)$ & $0.95(0.79-1.14)$ & $1.04(0.75-1.44)$ \\
\hline
\end{tabular}


Table 3: Comparison of the prevalence of patients with home dialysis by distance from nearest home dialysis unit

${ }^{*} \dagger$ Adjusted for median age, race distribution, median per capita income, $\%$ unemployment, and $\%$ population under the poverty level

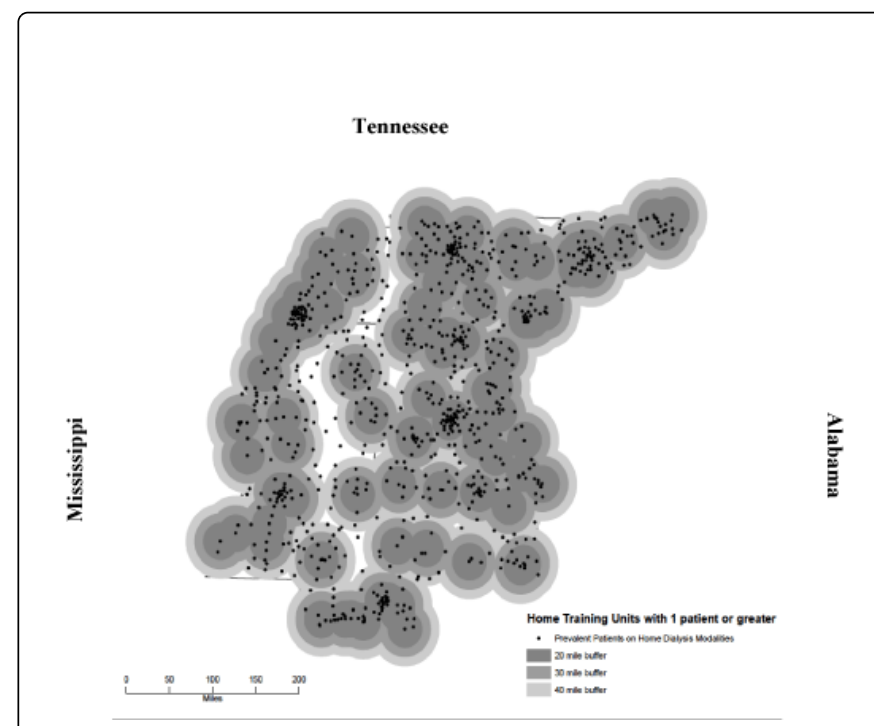

Figure 2: Home dialysis patients in relation to HDU on a map of Alabama, Mississippi, and Tennessee. Black dots represent zip codes where prevalent patients on a home dialysis modality reside. Each dot may represent more than 1 patient. Larger circles represent zip codes where an existing HDU is located. Different shaded circles are at 20 mile, 30 miles and 40 miles from the home training unit.

\section{Discussion}

The utilization of home dialysis in rural and remote areas has advantages for the unique needs of this population. As one would predict, two previous studies have shown that utilization of home dialysis in the United States increases the farther one lived from a home dialysis unit [6,7]. Likewise, a recent study from Australia showed that home dialysis utilization increased with remote location and that this increase was largely driven by decreased socioeconomic status [8]. However, the current research suggests that these studies are not generalizable to ESRD Network 8, a network in the southeastern United States. Our study did not show a difference in rural utilization of home dialysis when compared to metropolitan areas or when analyzed by distance to any existing HDU. Furthermore, after adjusting for socioeconomic characteristics these data still remain true despite the decreased socioeconomic status of the zones from which patients were analyzed.

Regional differences with respect to access to home dialysis care may explain the reason for the lack of increase in home dialysis utilization in rural areas and at increasing distance from a HDU. Network 8 as compared to the data reported by Prakash et al., only $33 \%$ as opposed to $55 \%$ of total dialysis units offer home therapies and
$20 \%$ of patients live outside of a 20 mile radius of a HDU as opposed to only $9.9 \%$ [8]. Thus, a larger percentage of the population must drive much farther distances in order to have access to home dialysis care than is shown in previous studies. Studies evaluating if this holds true for access to in-center hemodialysis in this region are needed to determine if this holds true for access to in-center hemodialysis as well. Other potential explanations for the differences shown in this research as opposed to existing studies could include regional variation in patient and/or physician attitudes towards the different dialysis modalities and varied topographic geography making distance alone an inadequate marker for remoteness.

It should be noted that the distances traveled to any HDU may not reflect the distance to quality home dialysis care. The size of a HDU is correlated with technique survival and mortality and has been used as a surrogate for home dialysis quality, with units more than 20 patients having better outcomes [5,9-12]. In ESRD Network 8, only $32 \%$ of all HDU had more than 20 patients while $30 \%$ had less than 5 patients. As such, geographic barriers may be even greater if patients wished to go to an HDU with more than 20 patients.

The fact that the prevalence of home dialysis does not change with increasing distance to a HDU shows that despite geographic barriers, patients who are capable both physically and financially are willing to travel significant distances to be on a home therapy. It is possible that rural utilization of home dialysis could be increased should this geographic barrier be removed. Possible ways to improve these barriers in access to care could be with the allowance of a telemedicine visit as a substitution for all or some of the face-to-face visits, a practice already being utilized widely in India [13].

This study has limitations. First, patients and facilities were classified by the center of each zip code where they were located as opposed to by their actual physical location. Also, the comparator zone analysis classifications were based on straight line distance to a home training unit as opposed to actual distance from the patient to the HDU. Travel time was not accounted for. Analysis of access to home dialysis by RUCC may be misleading, as it ignores the actual dialysis facility locations and assumes equal distribution of HDU. Socioeconomic characteristics were of the total population in each zone and not of the patients themselves due to limitations in access to patient specific data. Finally, the total number of patients in the $>40$ mile from an HDU zone and in rural areas was low and as such may be underpowered to detect differences in home dialysis utilization.

In conclusion, studies addressing the accessibility of home dialysis utilization combining geographically, culturally, and socioeconomically diverse groups are inadequate to address the unique regional differences and thus cannot be used to guide policy to improve access to care. It is the interplay of multiple complex regional variations such as geography, cultural views on care, public health initiatives, among others that accounts for much of the worldwide variation in home dialysis utilization rate [14]. More studies looking at these unique regional differences are needed in order to guide policy and determine worthwhile interventions to increase patient access to home dialysis care. 
Citation: Wallace EL, Griffin RL, Koenig KL, Crain LA (2014) Regional Impact of Geography on Home Dialysis Utilization. J Nephrol Ther 4: 176. doi:10.4172/2161-0959.1000176

Page 5 of 5

\section{Acknowledgments}

Research reported in this publication was supported by the National Center for Advancing Translational Sciences of the National Institutes of Health under award number UL1TR00165.

\section{References}

1. US Renal Data System: Bethesda, US Department of Public Health and Human Services, Public Health Service, National Institutes of Health, 2013 USRDS Annual Data Report. 2013

2. Mehrotra R, Marsh D, Vonesh E, Peters V, Nissenson A (2005) Patient education and access of ESRD patients to renal replacement therapies beyond in-center hemodialysis. Kidney Int 68: 378-390.

3. Mehrotra R, Kermah D, Fried L, Kalantar-Zadeh K, Khawar O, et al. (2007) Chronic peritoneal dialysis in the United States: declining utilization despite improving outcomes. J Am Soc Nephrol 18: 2781-2788.

4. Mehrotra R, Blake P, Berman N, Nolph KD (2002) An analysis of dialysis training in the United States and Canada. Am J Kidney Dis 40: 152-160.

5. Mehrotra R, Khawar O, Duong U, Fried L, Norris K, et al. (2009) Ownership patterns of dialysis units and peritoneal dialysis in the United States: utilization and outcomes. Am J Kidney Dis 54: 289-298.

6. O'Hare AM, Johansen KL, Rodriguez RA (2006) Dialysis and kidney transplantation among patients living in rural areas of the United States. Kidney Int 69: 343-349.
7. Prakash S, Coffin R, Schold J, Lewis SA, Gunzler D, et al. (2014) Travel distance and home dialysis rates in the United States. Perit Dial Int 34: 24-32.

8. Grace BS, Clayton PA, Gray NA, McDonald SP (2014) Socioeconomic differences in the uptake of home dialysis. Clin J Am Soc Nephrol 9: 929-935.

9. Afolalu B, Troidle L, Osayimwen O, Bhargava J, Kitsen J, et al. (2009) Technique failure and center size in a large cohort of peritoneal dialysis patients in a defined geographic area. Perit Dial Int 29: 292-296.

10. Huisman RM, Nieuwenhuizen MG, Th de Charro F (2002) Patientrelated and centre-related factors influencing technique survival of peritoneal dialysis in The Netherlands. Nephrol Dial Transplant 17: 1655-1660.

11. Guo A, Mujais S (2003) Patient and technique survival on peritoneal dialysis in the United States: evaluation in large incident cohorts. Kidney Int Suppl : S3-12.

12. Schaubel DE, Blake PG, Fenton SS (2001) Effect of renal center characteristics on mortality and technique failure on peritoneal dialysis. Kidney Int 60: 1517-1524.

13. Nayak A, Karopadi A, Antony S, Sreepada S, Nayak KS (2012) Use of a peritoneal dialysis remote monitoring system in India. Perit Dial Int 32: 200-204.

14. Wilkie M (2011) Home Dialysis-an international perspective. Nephrol Dial Transpl Plus 4[Suppl 3]: iii4-iii6. 